\title{
Creating the requirements to the national platform "Digital Agriculture"
}

\author{
V.I. Medennikov ${ }^{1}$, A.N. Raikov \\ dommed@mail.ru, alexander.n.raikov@gmail.com \\ ${ }^{1}$ Federal Research Center "Informatics and Control" RAS, Moscow, Russia \\ ${ }^{2}$ Institute of Control Sciences RAS, Moscow, Russia
}

The paper addresses the issue of creating the requirements for the development of the Russian national platform "Digital Agriculture" on the bases of collecting, formalizing and analyzing data on the current and forecasting states of the processes of using digital technologies in the agricultural economy sector at the federal and regional levels, as well as the world experience of digitalization. The national strategy agriculture goals were used as the criteria for analyzing the situation connected with the issue of creating the national platform. Currently, the agricultural sector of the country's economy has more than ten large information systems that require to be integrated to achieve the goals of the country's agricultural development. The list of problems of developing the processes of agriculture digitalization was made. The special author's convergent strategic methodology was used for formulating the requirements that ensure the conditions for the purposefulness and sustainable convergence of the process of creating the national platform. About fifty requirements were formulated for creating sub-platforms and digital services of the national platform "Digital Agriculture". It was also used the methods of cognitive modelling and the inverse problem solving for taking into account changes in the importance of roadmap's events of making the sub-platforms and digital service over time

Keywords: cognitive modelling, convergent approach, digital agriculture, national platform, requirements, strategic planning.

\section{Introduction}

Digital agriculture refers to agriculture based on using of end-to-end digital technologies and data supplied by the digital sector of country's economy. The process, based on an introduction of modern digital technologies, is called digital transformation. Digitalization affects all components of the agricultural sector and the activities in it, including at the federal, regional, municipal and corporate levels.

Digital platforms are switching the construction of separate and modular technical infrastructures to integrate ecosystem's solutions by creating semantically interoperable bridges between people and technologies, supporting new efficient business models and the generation of new values.

The goals of Russian agriculture development are approved by the state government. The analysis of the regulatory and administrative documents gives the possibility to identify about 40 goals that can be used as the criteria of the national platform development. The main goals can be summarized in the following list (arranged in descending order of importance):

- Increasing the competitiveness of agricultural products on the global market,

- Improving food security and independence,

- Ensuring the growth of the physical volume of investments,

- Increasing the added value,

- Developing of the agriculture infrastructure,

- Improving the quality of living of the rural population,

- Increasing the volume of disposable resources of households,

- Implementing an innovative and breakthrough ideas,

- Increasing business reputation on the global market, etc.

These goals were used as the criteria for analysis the situation connected with the issue of creating the national platform "Digital Agriculture" (digital ecosystem). The analysis and synthesis of the requirements of making the national platform "Digital Agriculture" was made with support some of strategic planning methods.

\section{Methodological approaches}

The following representative approaches and methods that have proven themselves in the global practice of strategic planning and digital transformation were used for analysis and synthesis the requirements:

- An architectural approach for creating large information systems,

- Methods of strategic analysis and planning,

- Project management methods,

- The quality functions deployment approach,

- Flexible design technologies (e.g. Agile, SAFe, Lean, Scrum, Kanban),

- The author's convergent approach and cognitive modelling [1].

The list of approaches is not limited by this. For example, various models can be used to analyze global changes in trade policy in the agricultural sector, assess unrealized trade potential, analyze elasticities of import demand and substitution elasticities between importers [2, $3,4]$. The partial equilibrium model, say, can be used, where the number of factors is reduced relative to global models. The methods of segmentation and prioritization of export of agricultural products, based on the big data analysis and gravity modelling, can also be used [5].

In world practice, some methods are used to scale the levels of technological development, such as assessing technological, production or market readiness, maturity assessment, development phase, technology profitability rating. These methods provide carrying out assessments harmonized with foreign metrics and were used too.

The main information for analysis was the data about the federal and regional agricultural information systems. The experience of various countries in creating such systems was also analyzed, as well as the following information:

- Relevant regulatory legal documents,

- Strategic planning documents and official statistics,

- Experience of using more than 40 retrospective agriculture information systems,

- Reports on previous digitalization surveys, 
- Development centers of competence in the field of the digital economy,

- Open databases in Russian and English languages (in Internet),

- Questionnaire data, focus groups, expert information,

- Scientific publications and citation data, library databases (open access), patent information,
- Electronic documents that are in the public domain and other sources.

The order of implementation the methodology of creating the requirements for development of the national platform "Digital Agriculture" is shown in Fig. 1.

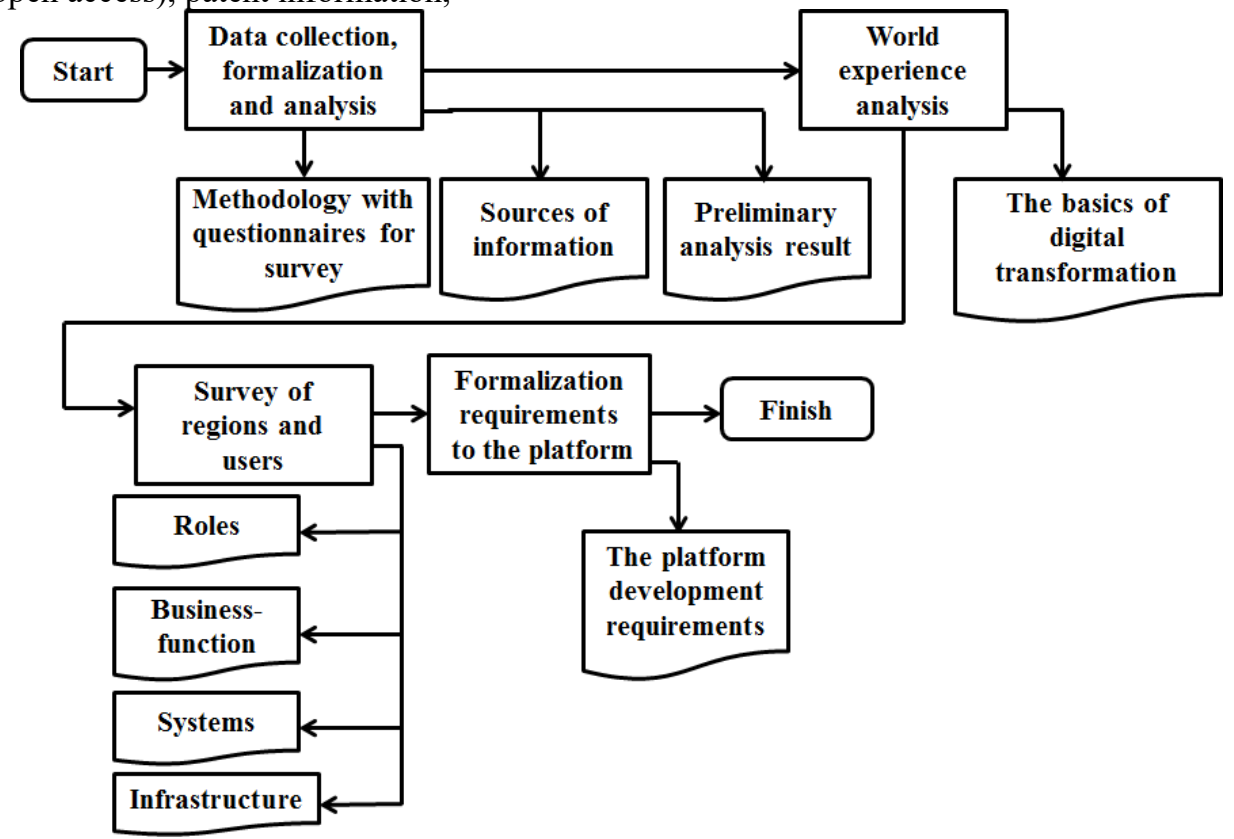

Fig. 1. The order of creating the requirements

For the purpose of the paper an appropriate guidelines was developed, which included a questionnaire for interviewing representatives of federal and regional authorities.

\section{Agricultural information systems}

\section{Federal information systems}

Currently, on the federal level the website of the Ministry of agriculture of Russia provides a list of the eleven information systems. They have to be integrated by the creation of the national platform (ecosystem) "Digital Agriculture", which is provided by the plans for the development of the digital economy in Russia. For example, there are federal agricultural information systems, as follow:

- The Federal state information systems for registration tractors, self-propelled machines and trailers for them,

- The Food security monitoring and forecasting system of the Russia,

- The system of providing public services in electronic form of the Ministry of agriculture of the Russia,

- The Information system for planning and control of the state program,

- The Automated information system of reference information, and others.

In addition to these working systems, the ones created in different years were also analysed: in the Ministry of agriculture of Russia-over 30 information systems; in the regions of Russia-various information systems used (traditionally) or proposed for use in these regions, e.g.:

- Automated information system "Agrostat",
- Electronic atlas of agricultural lands,

- Remote land monitoring system,

- Accounting for agricultural machinery,

- Passports of the regions,

- Electronic State Services,

- System for monitoring and forecasting the food security of the Russian Federation,

- Cartography, etc.

Each of the listed systems was analysed by: purpose, composition of the functions performed, and use by departments of the Ministry of Agriculture of Russia, composition of components, interaction with other systems, stored and generated information. For example, the first of the listed systems is designed to: automate monitoring processes in the main areas of agricultural activity in Russia, monitor indicators of the implementation of the State Program for the Development of Agriculture, regulate markets for agricultural products, raw materials and food, implement federal targeted programs for agricultural development, support management decisions and the formation of a transparent information environment. It implements many functions. The system consists of interconnected sites hosted in the Internet, providing automation of data collection departmental statistical reporting monitoring the completeness and quality of incoming information, its primary analysis, and the formation of various types of summary reports. But there are no reports on the real interaction of "Agrostat" with the other Ministry of agriculture of Russia's systems, and requirements for ensuring the semantic interoperability of such interaction are clearly not found. 


\section{Regional information systems}

The list of regional information systems was compiled, including, for example, the following systems:

- Automation of the calculation of the size of state support,

- Calculation of subsidies for agricultural producers with personal accounts,

- Analysis of the financial and economic condition of agricultural producers,

- Subsidies for agriculture,

- Formation and reporting,

- System of information exchange on soft loans,

- Operational monitoring of seasonal indicators by regions,

- Coordination of target indicators, etc.

The list was created by using the information from the answers to the questionnaire of representatives of the regions. As a result of a regional survey, the main barriers that must be overcome for the successful implementation of the national digital platform project were identified, e.g.:

- Lack of harmonization of legislation at the international level,

- Various standards of Russian participants in the field of digitalization and information security,

- Various standards of international participants in the field of digitalization and information security,

- Inability of using smart contract technology,

- $\quad$ Lack of an effective intellectual property management system,

- The difference in product delivery costs among participants,

- Insufficient maturity of critical digital infrastructure,

- Lack of mechanisms to ensure the growth of competitiveness of products,

- Non-optimal transaction insurance mechanisms, etc.

The regional survey shows the needs in follow actions: changing legislation, applying end-to-end digital technologies, gaining new information, automating business functions, using information systems, infrastructures, etc.

\section{World experience of agriculture digitalization}

\section{Bulgaria}

Bulgaria approves digitalization strategy for agriculture and rural areas [6]. It aims to make Bulgarian agriculture a high-tech, sustainable, highly productive and attractive element of the global economy, as well as improve the living conditions of farmers and rural residents. The strategy includes a digitalization action plan that involves the implementation of the following sections:

- Creation digital infrastructure for communication,

- Investments in modernization and precision farming technologies,

- Development of digital networks and software applications for business management and decisionmaking,
- Providing training and consultations on the development of digital skills and advanced training, etc.

Bulgaria has a tendency of a transition to precision agriculture, the use of unmanned vehicles (primarily combines and sprayers) and drones (for monitoring and protecting farmland), and software for smart farms. Local companies offer sensors that track soil performance and allow to accurately determining the amount of water needed for irrigation at any given time.

\section{Kingdom of Denmark}

Geo-information technologies, multi-operational energy-saving agricultural units, selection of high-yielding plant varieties and breeding of highly productive animal breeds, the creation of biologically active feed additives, new medicines for animals, modern methods of combating epizootics, quarantine diseases of animals and plants are widely used in the country.

The digitalization of agriculture is widely sought after by Danish agribusiness. It contributes to the intensive technological development of the industry, as well as to the growth of productivity and competitiveness of Danish agriculture. In Denmark, in the process of digitalization of agriculture, two trends stand out: "precision agriculture" and "precision livestock farming".

\section{United Kingdom of Great Britain and Northern Ireland}

At the beginning of 2018, the British government published the document "Industrial Strategy: building a Britain fit for the future", which outlines the government's plans to modernize and introduce information technologies (IT) in all sectors of the economy. The government intends to "move" agriculture to the position of a highly efficient and highly industrial sector of the economy.

UK agriculture currently is in a transitional phase of its evolutionary development. The introduction of IT allows optimizing the activities of all workers, reduces the cost of producing a unit of production. It helps farm owners making right decisions in a timely manner on issues such as tillage, sowing, fertilizing, the use of protective equipment, etc.

British farmers are actively using smartphones and personal computers to order the seeds, fertilizers, and protective equipment for sell their products through specialized sales sites. The government decided to create a specialized platform (ecosystem) for collecting, processing and storing agricultural Big Data. Radiocontrolled aircraft are increasingly used in UK agriculture.

In the UK, for the first time in world practice, in 2018 , a winter wheat without human intervention was grown on an area of 1 ha. All operations for processing the experimental plot, sowing, caring for the sowing and threshing of winter wheat were carried out by robotic selfpropelled agricultural machines and mechanisms.

\section{USA}

The country's agricultural development strategy (20182022) considers increasing the efficiency of information 
collection and processing by digitalizing the agroindustrial complex as one of the key tools for achieving the target agriculture indicators.

In accordance with its main provisions, the US Department of Agriculture encourages promising development of robotics and electronic applications to improve agricultural production systems. State support for research on innovative technologies in agriculture in the US in 2019 amounted to $\$ 2.5$ billion.

Since 2011, the agency has been collaborating with one of the largest US companies in this field ESRI on the development of a geospatial portal. Through the portal, the US Department of Agriculture and other government agencies access valuable web maps and agricultural datasets and can use spatial analysis functions. Users have communication and data exchange tools that are available in the ArcGIS Online public cloud mapping environment [7]. It is used as a convenient tool for the search, discovery and sharing of geospatial content, including those related to responding to natural disasters.

In the US there are a large number of organizations, which are specializing in various segments of agricultural activity: animal husbandry, seed production, etc. A detailed analysis of their activities has been carried out; promising areas of research and requirements for creating the Russian digital agriculture platform was identified.

\section{Russia agricultural sector and its digital problems}

Currently, it can be distinguished the following different and separated areas of digital transformation of Russian agricultural sectors:

- Creation of an information management system,

- Precision agriculture,

- Active implementation of automation systems and robots,

- Revision of ideology and technology of enterprise management,

- Integration of single databases (clouds) of scientific information resources.

A large number of companies are appearing on the agriculture market. They offer various individual digital technologies that are heterogeneous. However, the current Russian IT agricultural architecture is characterized by:

- Duplication of functions and tasks implemented by various application systems,

- Using for implementation of the same functions with various software tools and systems,

- The absence of guarantees of the coincidence of the values of the same indicators contained in the database of various information systems,

- Using various formats and forms of data exchange,

- Lack of a unified methodology,

- The lack of unified technological mechanisms and uniform regulations for the collection of information from data sources,

- Lack of centralized management of information resources consolidated at the federal and regional levels,

- High complexity of developing processes of application systems, etc.
Regional agribusiness entities provide information on fertility, fertilizing, using of chemicals, crops, etc., but the information does not represent a clear picture of what is happening in the fields, in particular, there is no enough data to track the spent funds from subsidies.

There is no integrated view on the design of information systems; there is no methodological and organizational support for the design, development and maintenance process, which has led to a deficit in the conceptual architecture of building the digital platform.

Ignoring scientific and educational resources prevent their transfer to the digital economy. Problems arose in creating new information technologies that provide the opportunity to extract the necessary knowledge. These problems have gained particular importance in the field of information accumulation in education and science.

More and more companies are offering automation of one or another separate technology with its own conceptual model of the subject area, implemented by different tools. For example, in agriculture about 20 geographic information systems are currently used. Following the task-oriented approach (also called the patchwork informatization) evaluation of the set of tasks to be solved in crop production shows the number about 150 tasks, various technological operations-about 20, regions-80, and cultures-20. It gives the requirement to make about 4,800,000 information systems. This is not considering the various technologies used in these systems, which is unacceptable.

In fact, there is a quantum leap in the technical complexity of new technologies, which requires a completely different level of design, competencies and performing discipline compared to what is currently available.

\section{Requirements for creating the national agriculture platform}

An analysis of the situation made it possible to create the list of about 50 requirements that must be implemented to create an effective national platform, various subplatforms and services in the field of agriculture, the main of the requirements are as follow.

The methodology for creating the national platform "Digital Agriculture" should be based on a comprehensive (hybrid) approach covering the methods and approaches listed in the section 2 .

It is necessary to provide an integrated view on the design of the national agriculture digital platform, including the creation of methodological and organizational support for the development and maintenance process, a balanced centralization of management of available information resources with the possibility of corporate use and interoperable interaction of application systems among themselves at all levels of management.

In the development and implementation of end-to-end digital technologies (E2EDT) in the field of agriculture, all seven basic E2EDT, for which roadmaps have been developed as part of the implementation of the national project Digital Economy of Russia, can be used. It is 
advisable to be guided by the following list (in descending order of importance):

- Artificial intelligence recommender systems,

- Sensors and robotic tools,

- Big data,

- Smart manufacturing,

- Optimization of data processing and transmission;

- Graphic output, development of VR/ R content, etc.

It is advisable to create a basic core of the national digital platform, which will provide synergies for solving the issues:

- Data openness for all platform participants,

- Interaction with the platform on open and unified protocols,

- Modular structure, etc.

It is necessary to ensure that each consumer of agricultural products could in real time checks information on the quality, safety and legality of products, and regulatory authorities-to gain access to the full range of product information.

It is advisable to use an information system developed by the Russian Academy of Sciences that provides a unified database of scientific and technological knowledge of the agricultural sector of the Russian economy, and with which agricultural enterprises of the regions are working and in which retrospective information is recording.

It is advisable to develop an intelligent information and analytical digital subsystem of management and decisionmaking support in the field of precision farming, taking into account the targeted implementation of subsidization processes.

It is necessary to create a Federal digital animal registration system for maintaining the list of animal (with identification of age, gender, cyclicity, and cross-border movement), ensuring veterinary safety, including among pigs, dogs and cats. The system should provide centralized accounting and planning.

It is necessary to eliminate the existing gap between the systems of collecting and processing primary information from production, science, territories, population and systems for collecting and processing secondary (collected and processed by various organizations) information.

It is advisable to develop the collective decision support making system, for which it is necessary to use geo-information data and methods, computer modelling and methods of organizing networked strategic conversations. During modelling the option of influencing the development of the situation of emissions of harmful substances into the atmosphere should be provided taking into account the dependence on the wind rose.

It is necessary to sharply expand the use of robotics, including unmanned aerial vehicles, for automatic assessment of soil parameters in a given field, the level of soil pollution, recognition and destruction of various types of weeds, as well as cow parsnip, including using mechanical devices and chemicals.

The list of requirements for creating the national agriculture platform can be followed. These requirements were taken into account during developing the roadmap of creating the national platform, including the following activities to create sub-platforms:

- Statistics collection,
- Providing information support and providing services,

- Digital land use and land management,

- Storage and distribution of information materials,

- Product traceability,

- Agrometeoprognosis.

With using the created requirements the plan of actions was made that included different main events for creating the national agricultural platform.

\section{Dynamic optimization of the action plan}

The events of the plan was compared and sorted by importance, taking into account that this importance will set the allocation of resources. To compare importance, for example, the hierarchy analysis method and the method of multi-criteria estimates of importance typically have been used [8]. But these are the static methods, which connect the assessments to the point of time. However, the importance of the evaluation criteria and the events themselves may change over time, and the interconnection of events must be taken into account: with the changing importance of one event, the importance of the others may change. In this case, dynamic optimization of decisionmaking on digitalization is required on the set of planned activities for creating the national platform "Digital Agriculture".

This paper proposes a dynamic analysis and takes into account changes in the importance of events over time. For this, it was used as the method of cognitive modelling, as the inverse problem solving method on a cognitive model using the genetic algorithm method [1]. Such modelling made it possible to find the optimal activities of the plan to achieve the goals of creating a national digital agricultural platform. In total, 11 of the most important activities of the roadmap were identified, which include:

1. Sub-platform for collecting statistics,

2. Sub-platform of information support,

3. Land use assessment services,

4. Digital land use services,

5. Unmanned aerial video filming service,

6. Service for the formation of a scientific base,

7. Sub-platform of information materials,

8. Crop Disease Monitoring Service,

9. Sub-platform of product traceability,

10. Sub-platform of meteorological forecasting,

11. Weather monitoring service.

The cognitive model of the relationship of the plan's events is shown in Fig. 2.

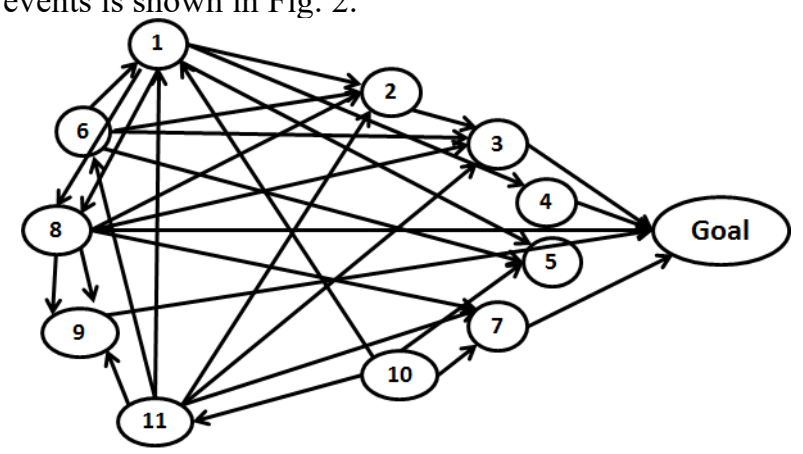

Fig 2. The cognitive model of the plan's events 
The modelling showed that the greatest emphasis in creating a national platform should be made at events 9, 7 and 1. An optimistic scenario for the development of a national platform can also be achieved by allocating the same funds for the development of all events except the event 1 . However, there may be the other scenarios that will lead to an optimistic result. For example, if the development of the event 1 is significantly strengthened, and the implementation of the event 10 is temporarily suspended, optimistic result will also be obtained.

\section{Conclusion}

The list of about the fifty requirements for the development of the national platform "Digital Agriculture" was created. The list of goals that were extracted from the regulatory and administrative documents was used as the bases for creating the criteria for developing the national platform.

The several strategic representative approaches and methods of strategic planning were applied for integrating the number of criteria. One of them was the special author's convergent strategic method that ensures the conditions for the purposefulness and sustainable convergence of the process of creating the national platform.

The significantly new in the paper was using cognitive modelling and the inverse problem-solving methods for optimizing the decisions regarding the important plan's events that can change over time. The interconnections of the plan's events were taken into account. Such modelling helps to find the optimal allocation of resources for the activities of the plan to achieve the goals of creating a national platform "Digital Agriculture".

\section{Acknowledgments}

The work was supported by the Russian Foundation for Basic Research, grant 18-29-03086.

\section{References:}

[1] Raikov, A.N., Panfilov, S.A.: Convergent Decision Support System with Genetic Algorithms and Cognitive Simulation. Proceedings of the IFAC Conference on Manufacturing Modelling, Management and Control, MIM'2013, Saint Petersburg, Russia, 1142-1147, 2013. doi: 10.3182/20130619-3-RU-3018.00404.

[2] Francois, J. and Keith, H.: Global simulation analysis of industry-level trade policy, mimeo, The World Bank, 2002. http://wits.worldbank.org/data/public/GSIMMethodo logy.pdf, last accessed 10.05.2020.

[3] Hertel, T., Hummels, D., Ivanic, M., Keeney, R.: GTAP Working Paper. How Confident Can We Be in CGE-Based Assessments of Free Trade Agreements? No. 26, 2003. https://www.gtap.agecon.purdue.edu/resources/down load/1533.pdf, last accessed 10.05.2020.

[4] Shoven, J.B., Whalley, J. Applying General Equilibrium, Cambridge University Press, Cambridge. 1992: URL: https://econpapers.repec.org/bookchap/cupcbooks/97 80521266550.htm, last accessed 10.05.2020

[5] Raikov, A., Abrosimov, V. Import Countries Ranking with Econometric and Artificial Intelligence Methods. Third International Conference Digital Transformation and Global Society, DTGS 2018, St. Petersburg, Russia, May 30 - June 2, 2018, Revised Selected Papers, Part I. 402-414, 2018. doi: 10.1007/978-3-030-02843-5_32

[6] The Bulgaria republic digitalization strategy for agriculture and rural areas. http://www.mzh.government.bg/media/filer_public/2 019/05/10/strategia_za_cifrovizacia_na_zemedelieto. pdf (2019), last access 10.05 .2020 .

[7] United States Department of Agriculture. https://www.ocio.usda.gov/about-ocio/enterpriseapplications-services-eas, last accessed 10.05.2020.

[8] Bartzas, G. and Komnitsas, K. An integrated multicriteria analysis for assessing sustainability of agricultural production at regional level, Information Processing in Agriculture, 2019, doi: 10.1016/j.inpa.2019.09.005

\section{About the authors}

Alexander N. Raikov, professor, doctor of technical sciences, State advisor of the Russian Federation of the 3rd class, Winner of the Russian government award in the field of Science and Technology, leading researcher of the Institute of control sciences of Russian academy of sciences, General director of the New strategies agency Ltd., Professor of the State technological university (Russia), Senior Researcher of the National center of excellence in the field of digital economy of the Lomonosov Moscow state university. E-mail: alexander.n.raikov@gmail.com

Victor I. Medennikov, professor, doctor of technical sciences, leading researcher of the Federal research center "Informatics and Control" of Russian Academy of sciences. Email: dommed@mail.ru, 